\title{
Web-based Simulation Modules as Supplement for Enhancing Learning in Lecture and Laboratory-based Engineering Courses
}

\author{
S.K. Chaturvedi' and R. Prabhakaran ${ }^{2}$ \\ ${ }^{1,2}$ Batten College of Engineering and Technology, Old Dominion University, Norfolk, Virginia 23508
}

\begin{abstract}
Results are presented from an NSF supported project that validate the hypothesis that students' learning gains can be enhanced through integration of web-based interactive simulation and visualization modules in engineering courses. The implemented modules were used in the "supplementation" mode wherein students used these modules along with conventional lecture or laboratory classes. In order to gage the effectiveness of each implemented module a "control" group, without access to the module, and an "experimental" group, with access to the module, were identified. Performance of students in both groups in an identical quiz was analyzed statistically to determine if the introduction of web-based modules favorably affected students' learning outcomes. Since both "control" and "experimental" groups may have different demographic profiles - different age, ethnicity, gender etc. - a demographic factor analysis was also conducted for each module to assess if the impact of demographic factors rises to the level of statistical significance.
\end{abstract}

\section{S.K. Chaturvedi}

Batten College of Engineering and Technology,

Old Dominion University, Norfolk, Virginia 23508
Results of statistical analysis indicated that of the twenty eight learning outcomes tested in eight engineering courses, fifteen showed statistically significant improvement in quiz scores for "experimental" groups over corresponding "control" groups. Even though for thirteen outcomes the quiz scores were generally higher for the "experimental" groups, improvement in quiz scores over the control group performance was not statistically significant. The demographic factor analysis also showed that whereas gender, ethnicity, course load and math SAT scores are not significant factors for the pedagogy of learning with the web-based simulation and visualization modules, the cumulative GPA was a significant factor in five out of nine modules.

The results presented in this large scale study, spanning over three engineering disciplines, demonstrates the favorable impact of web-based simulation and visualization modules on student learning. The project has not only led to enhanced student learning in engineering courses and faculty development but it has also contributed to engineering pedagogy by demonstrating the effectiveness of webbased simulation and visualization modules when used in the "supplementation" mode with conventional lectures or lab classes.

Keywords: Visualization, Simulation, Assessment, Web-based Modules. 


\section{Introduction}

Engineering education enterprise faces major challenges in its effort to recruit and retain a diversified student body, as documented in the National Science Board report "Moving forward to improve education"[1]. A majority of engineering students until recently have been educated using the teacher-centric learning(TCL) pedagogy in which knowledge transfer to students occurs primarily through instructor-led lecture classes[2]. In this educational model, students receive information passively without being actively involved in their own learning process. Despite its successful track record of educating engineers throughout the 20th century, and its universal appeal to engineering educators, the TCL educational model has come under criticism for being outdated and not being in sync with profound societal changes brought about by the digital revolution. To compound the problem further, most engineering professors have continued to use a deductive teaching style that relies primarily on complex equations and mathematical operations to explain engineering concepts and principles to students. This teaching style is currently in vogue in academia primarily due to engineering educators' own doctoral research training that relies heavily on analysis and mathematical operations for problem solving. Due to the absence of training geared towards development of teaching skills, most newly minted engineering doctorates have backgrounds that are generally skewed more towards disciplinary research expertise and less towards teaching and communication skills that are considered critical for educating undergraduate students in the current learning environment.

Students find this teacher-centric approach to their education inhibitive in their quest for learning, since a majority of them fall into the category of visual learners [3]. Visual learners typically prefer charts, diagrams, visual images, computer graphics and animation for subtle concepts and principles. The digital revolution, marked by rapidly developing computer, video and internet technologies, has pushed the current generation of engineering students further in the camp of visual learners. This clash of opposite teaching and learning styles has created a perception among students of lack of faculty commitment to their education and success. The engineering profession is also viewed by many as not being sufficiently diversified with respect to minorities and gender [4]. The low level of students' persistence especially in large freshman and sophomore engineering classes has often been attributed to the teacher-centric style that is regarded by many students as uninspiring. TheUS President's Council of Advisors on Science and Technology(PCASTS) notes the following in its report "Engage to Excel: Producing One Million Additional College Graduates with Degree in Science, Technology, Engineering and Mathematics:" "Moreover many students, and particularly members of groups underrepresented in STEM fields, cite an unwelcoming atmosphere from faculty in STEM courses as one of the reasons for their departure" [5]. Engineering education is also being impacted by a sharp increase in non-traditional students who follow a $2+2$ track that involves spending two years at a community college followed by the remaining two years at a 4-year college. This transition can be challenging for most students in general but minority students in particular [4]. The reason is that while faculty in community colleges are dedicated primarily to teaching and mentoring of students, most faculty in four-year engineering colleges are required to be actively involved in funded research and scholarly activities. This leaves them less time for addressing issues such as student learning, retention and graduation.

Many non-traditional students also pursue engineering degrees on a part-time basis while holding full-time jobs. This group also includes those who enroll in engineering programs due to mid-career shift in professional goals. Some of the non-traditional students lack proper background in mathematics and also time management skills to balance their work schedule with academic activities. Since these students are generally distributed geographically near their employment locations, they universally seek web-based educational resources that can be accessed in the anytime/anywhere mode. This has led to proliferation of web-based distance learning courses and programs in recent years. In a paper titled "Online Engineering Education: Learning Anywhere Anytime", the authors have discussed online distributed learning for distance learners [6]. The relative merits of online versus conventional learning has been addressed in Ref.7.

An additional barrier to student learning is the current practice ofoffering large enrollment classes in sophomore and junior level engineering science courses. This has led to a general lack of two-way communication between instructors and students, and this has in turn transformed students into passive 
listeners. Students' passivity in lecture classes is further exacerbated by a complete collapse of students' interaction with instructors outside the classroom-during instructors' posted office hours. Although the causes of this recent phenomenon are not readily apparent, many professorsbelieve that it may be an outcome of an exponential growth in digital device usage among students that encourages connectivity in the virtual domain but adversely affects the face-to-face interactions in educational as well as social settings. Recent studies have shown that students' active participation in the learning process, referred to in the literature as active learning, leads to enhanced learning and better student retention [8-12]. Recent developments in technology, coupled with student demographic changes, are beginning to have a disruptive effect on the long standing teacher-centric model for educating engineers. Computer and webtechnologies are making it possible to develop and offer engineering courses, and in some cases the entire curriculum, on the web. These digital technologies have enormous potential for reshaping engineering education by aligning it more closely with the visual learning style of current engineering students and also address the needs of geographically distributed students. In order to address these problems and to bring about transformative changes in engineering education pedagogy- from TCL to students-centered learning (SCL)-engineering educators have created many active learning tools such as web-based multimedia modules [13-17] and virtual labs [18-26] that can be accessed by distance learners as well as campus-based students.

\section{Transformative Changes in Engineering Education at Old Dominion University}

In this section we describe the approach taken in the present study to promote active learning in engineering courses at ODU. This should hopefully address one of the major problems at ODU as well as at institutions elsewhere namely - the student passivity-in the learning process. The pedagogical changes implemented during the project should help decentralize the learning process and empower students to learn on their own, using web-based tools integrated in targeted courses. Discussion of these and other prevailing issues in engineering education among the Batten College of Engineering and Technology (BCOET) faculty over a period of nearly one year prior to undertaking the present study led to the formation of an engineering education project team of like-minded engineering professors. This project team conceived, developed, implemented and assessed strategies and tools to achieve transformative changes for revitalizing engineering education at ODU. The team also wrote several proposals to funding agencies and received both external and internal (university) funding geared towards enriching students' learning experience by making it more student-centric (autogogy).

The results presented in this work are from a recent NSF grant titled "Implementation Grant-Simulation and Visualization Enhanced Engineering Education". The primary goal of this department level reform(DLR) grant was to infuse courses with technology-based tools such as web-based visualization and simulation modules. Effects of this college-wide transformation of courses on student learning was assessed and analyzed using statistical methods. A team of twelve faculty members drawn from civil, electrical and mechanical engineering disciplines participated in this project. An active learning environment employing web-based interactive simulation and visualization modules was created and integrated in courses taught by the participating members. These modules were used only in the "supplementation" mode and provided students additional pathways for augmentation of learning achieved through conventional in-class instruction.

Although several previous studies involving webbased interactive modules and virtual labs have appeared in the literature in recent years[13-26], two factors set the present study apart from previous studies on this topical area. First, unlike many previous studies dealing with one or two modules in a given course, the scope of the present study is quite broad, involving several courses, faculty and disciplines. Consequently, it should be expected that results from the study would not only demonstrate the effects of individual(course) treatment, but they are also likely to provide a system level response to the proposed methodology. The second factor that makes the present study distinct from previous ones is that students' learning gains through implementation of web-based modules are assessed for a number of courses using an identical assessment methodology. A detailed statistical analysis, using non-parametric methods, of the effects of demographic factors on student learning makes the present study by far the most extensive. The systematic approach taken in this study is expected to make the pedagogy of supplementing classroom instruction with the web- 
based simulation and visualization modules more portable to other similarly situated engineering institutions.

A diverse mix of courses and differing methodologies used in them led to the following fundamental question in the module development phase of the project - Is it possible to establish a common ground for courses from all three disciplines so that a uniform framework can be used for incorporating web-based simulation and visualization modules in targeted courses? After extensive discussion, a consensus emerged among participating faculty that instead of prescribing a one- size- fits- all approach it would be more desirable to provide flexibility and latitude to faculty in the module development phase while requiring them to incorporate certain elements and characteristics identified during the initial phase of the project. The common elements identified are: 1) visualization of physical phenomenon, 2) simulation of physical process and 3) integration of virtual experiments in courses. In order to meet the criteria for the successful transformation of the course, at least one of the three elements must be present in the modules. Also, in order to maximize the impact of visualization and simulation on student learning,every module was required to include one or more of the following characteristics.

1) Interactivity; it refers to the student ability to interact with a module by facilitating input and output of data. This characteristics is expected to transform student learning from passive transfer of knowledge to an interactive student-centered learning environment which engages students to generate data from modules and provides opportunity to interpret them.

2) Practicality; it refers to the module emphasis on the engineering context of governing equations and principles underlying the module.

3) Interconnectivity; it is a module characteristic that refers to building on student's knowledge and experience in preceding subject materials and incorporating it in the present module.

4) Hierarchical ; this refers to module's capability of guiding students from elementary concepts to more advanced learning through sub-modules that are arranged hierarchically, with the succeeding submodule providing a higher level of learning compared to the preceding one.

All modules in this study have at the very minimum included "interactivity" characteristics. Faculty members were given the flexibility to incorporate additional module characteristics depending on the module subject matter.

Two types of web-based virtual modules have been developed and implemented in this study. The first type, the simulation and visualization modules, has been used in lecture courses. Although no specific guidelines were given, students used them for either preparing for the upcoming lectures and/or for reviewing the course material after it had been presented in lecture classes. In the second type of modules, the virtual labs, the objective was to prepare students for the physical experiments in the laboratory. Students used the virtual experiments prelab practice sessions to become familiar with the experiment objective and procedure. For this purpose, several physical experiments in two-labs namely the thermo-fluids and the solid mechanics labs were mapped into interactive virtual experiments. Cataloging of important experiment attributes and student activities and preserving them in the physical to virtual mapping was an important step in the design and development of virtual experiments. Two examples of web-based modules are given in the websites:

www.mem.odu.edu/thermostates (thermodynamics lecture course)

http://www.mem.odu.edu/instrumentselection/dashb oard-new3.swf(thermo-fluids lab course)

www.mem.odu.edu/mohrscircle(solid mechanics lecture course)

http://www.mem.odu.edu/bendingexperiment(solid mechanics lab course)

Note: The best way to access these links is through Mozilla Firefox web browser.

\section{ExperimentalDesign}

\section{Control and Experimental Groups:}

In order to analyze the effects of a treatment in engineering education research one may employ a quantitative and/or qualitative method [27]. In the 
present study, a quantitative method has been used for assessing most modules implemented during the project. This method has been used to investigate if the proposed use of web-based modules, used in supplementation mode, enhances students` learning above and beyond the level achieved through conventional classroom instruction. For all modules, a number of objectives and outcomes were formulated and the module contents were developed accordingly. The number of objectives and outcomes varied from one course to another primarily due to the diverse nature of disciplines considered in this study. The "Intact group" method was used to assess the impactof modules on student-learning [28]. Based on this method, for modules regardless of discipline, a "control" group and an "experimental" or "treatment" group were created from the population of targeted students. The "control" group, also referred to as the "pre-implementation" or "without module" group did not have access to web-based module. Learning of the subject matter for students in this group was achieved primarily through instruction in conventional lectures and/or laboratory courses. Students in the "experimental" group, also referred to in this study as the "post-implementation" or "with module" group, supplemented their in class learning with the webbased module. In all courses prior to introduction of the module, students in a class in the previous semester were taught conventionally and this group was designated as the "control" group. In the following semester, the module was introduced in an entirely different class of the same course and it was designated as the "experimental" group. This procedure permitted the instructors to collect the baseline data in a manner similar to the one described in [27], and used by Kashy et al. [29]. This phased approach to assessment eliminates the cross-over effect in which students in the "control" group may get unauthorized access to web-based modules to improve their academic performance, thereby corrupting the data and affecting the outcomes.

Both "control" and "experimental" groups were administered an identical quiz or test to assess students` knowledge of the subject areas related to the introduced module. All other factors remaining the same, an increase in the quiz average for the "experimental" group above the "control" group average should be attributed to the module. However, there are factors other than the module, for instance student demographic factors such as gender, ethnicity, academic background etc. that may affect students` performance in the quiz. Measurement of student- learning is a very challenging task, since it is generally influenced by a myriad of parameters. In order to illustrate our present approach, a formal relationship between learning as measured by quiz or test scores, and other variables $\mathrm{x} 1, \mathrm{x} 2, \ldots . \mathrm{xn}-$ the demographic factors - is assumed to exist. The learning functions for the "control" group and the "experimental" group can be expressed symbolically as,

(Learning) control=

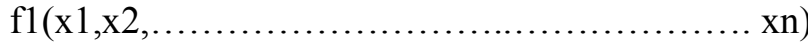

(Learning) experimental $=\mathrm{f} 1(\mathrm{x} 1, \mathrm{x} 2, \ldots \ldots \ldots \ldots \ldots$. $\mathrm{xn}$, module)

In order to account for different demographic factor profiles for the "control" and "experimental" groups, a statistical analysis is needed to determine if any of the variables $\mathrm{x} 1, \mathrm{x} 2, \ldots . \mathrm{xn}$ are statistically significant for the observed learning-gain for each module. Previous researchers such as Nguyen and Paschal [30] have used a variation of the Randomized Control Trial (RCT) method that uses a stratified random sample to ensure that a chosen (demographic) variable is equally represented in both "control" and "experimental" groups. Since faculty do not have any control over the student registration process, a matching to achieve parity in both "control" and "experimental" groups with respect to certain demographic parameters was not possible. Consequently, a statistical analysis of observed outcomes was done to characterize the effect of demographic factors on student-learning even though these parameters were not matched in "control" and "experimental" groups.

\section{Data Collection Process:}

Although data collection process was individual faculty responsibility, the process was standardized to stream line data collection and analysis. Standard grade book data containing "Without module" (= "control") and "With module" (= "experimental") outcomes in the form of numeric scores for quizzes and final total with Student University Identification Number (UIN) were first collected from instructors. Subsequently, grade book data were sent to the office of Institutional Research and Assessment (IRA) to further match and join the outcome data to student demographic data using Student UIN as a common key attribute. Once joined, student UIN was then deleted from the data set to ensure compliance with the Family Educational Rights and Privacy Act 
(FERPA) [31]. Selection of student demographic data categories were based on their potential influence/contribution to students` performance such Degree Major, Gender, Age, Attempted hours, Pass Hours, Associate degree, Cumulative GPA, Current class load, Math SAT ( Scholastic Aptitude Test) scores and high school GPA (Grade Point Average).

Statistical Analysis of Assessed Data and Test of Hypothesis

Since sample sizes varied from about 15 to 40 in most courses, the sampled outcomes may not be normally distributed for class enrollment below 30 students. Student outcome data set with demographic data were tested first for normality using a standard Shapiro - Wilk W statistics [32] at 95\% confidence level $(?=0.05)$. For majority of courses, Shapiro Wilk W statistics for outcomes were significant indicating that distribution of sample outcomes are not normally distributed at $?=0.05$ level. To address the issue of non-normality of quiz data, a medianbased, one-way wise pair non-parametric WilcoxonRank Sum Statistics [33] was used to test the hypothesis on the central tendency and dispersion in place of typical T-test to compare paired median as well as variance of all course outcomes at $95 \%$ level of confidence $(?=0.05)$.

In order to establish the efficacy of modules in enhancing student learning the following null and alternative hypothesis were tested.

Ho : $\mu[$ Course Outcomes $\{$ Without Module $\}]=$ $\mu[$ Course Outcomes $\{$ With Module $\}]$

Ha : $\mu[$ Course Outcomes $\{$ Without Module $\}]<$ or $>$ $\mu[$ Course Outcomes $\{$ With Module $\}]$

At 95\% confidence level, if Wilcoxon Rank-Sum pvalue is less than 0.05 , then a conclusion can be made that there is a significant difference between the mean scores of the course outcome being compared at their population levels, or mean scores of the student performance under "Without Module" (=Control) and "With Module" (=experimental) settings are different. After "Without Module" and "With Module" comparisons were done, hypothesis on the course outcomes were subsequently tested again in conjunction with students' demographic data to identify any potential influence of demographic factors towards the course outcomes.
Module Effectiveness in Enhancing Student Learning

The joined outcome data sets, incorporating student performance data together with the demographic data was analyzed using the methodology described earlier. Table 1 provides the rank-sum method $p$-values for each outcome. The pvalue is a measure of the contribution of chance factor to the observed outcome. It is a probabilistic measure of the fact that observed results for tested outcomes may not have occurred by chance. A value of $p$ less than 0.05 has been used as an indicator that observed results are unaffected by chance factor. Consequently the null hypothesis $\mathrm{HO}$ is rejected with $\mathrm{p}<0.05$, and any improvement in student learning, characterized by improved quiz scores, is attributed to the module implementation. Table 1 provides the details in the form of p-values for each outcome, obtained from the statistical analysis. The last column in the table summarizes conclusions based on p-values. Results in Table 1 indicate that of the 28 outcomes tested, $15 \mathrm{had}$ a p-value less than 0.05 . For remaining outcomes, the quiz scores improved but the improvement in quiz scores for the "experimental" group was not statistically significant. In every course module there was at least one outcome that showed improvement in student learning that was statistically significant. Consequently, one can conclude that implementation of web-based modules did enhance student learning in all the courses included in this study.

\section{Demographic Factors Analysis}

Since demographic factors such as gender, ethnicity etc. can impact student learning, a detailed analysis was also undertaken for each of the modules listed in Table 1. (Ideally, if none of these demographic factors considered in this study are not statistically significant $(\mathrm{p}>0.05)$ then one can reasonably conclude that student learning enhancement is only due to module introduction in courses). However, as results show, the module outcomes may display bias towards certain demographic parameters.

Table 2 presents the summary of results from the statistical analysis of demographic factors as contributing factors to student learning enhancement. All ten demographic factors are listed against the courses analyzed. The symbol "NO" indicates that the demographic factor is not a significant factor. The symbol "NA" indicates that a demographic factor data were not available. This was the case for the ECE 201 
course for which the statistical analysis did not include demographic factor analysis. Also, for the ME 305 course - module II, the demographic factor analysis included only seven factors, due to nonavailability of data for the remaining three factors. One significant finding of the demographic factor analysis is that for all modules shown in Table 2, "gender", "ethnicity", "course load" and "Math SAT scores" are not significant factors. "Age", "SAT verbal score" and "student track" (transfer versus freshman) are significant factors in only $11 \%$ of the modules (one out of nine modules) "Student level" (senior versus junior) is a significant factor in two of the nine modules (22\%). The "HS GPA" is a significant factor in three out of nine modules (33\%). The "cumulative GPA" is a significant factor in five of the nine modules (55\%). Students in the high "cumulative GPA" group benefited disproportionately from the module introduction as compared to students in the low "cumulative GPA" group. This is not a surprising result since students in the high "cumulative GPA" group are generally more likely to interact with these web-based learning tools compared to students belonging to the low "cumulative GPA" group.

\section{Conclusions}

The department level reform (DLR) grant awarded to Old Dominion University has created opportunities to revitalize engineering education through the use of technology tools such as simulation and visualization. The web-based modules developed and implemented for supplementation of in-class student learning have provided three major benefits for engineering faculty and students at ODU. They are:

\section{( Student learning enhancement}

\section{口 Faculty development}

u Pedagogical contributions to engineering education.

\section{Student Learning Enhancement}

Student learning enhancement is the foremost objective of this project. Assessment of student learning gains due to implementation of modules in engineering courses was accomplished, using credible experiment design and rigorous statistical analysis. Both these aspects of the assessment methodology used in this project are important if the results are to be applicable to a larger population of engineering students fromother institutions. Statistical analysis of the assessed data shows that implemented modules were effective in enhancing student learning. Nearly $65 \%$ of the outcomes related to ten modules in eight courses supported the above conclusion. For the remaining $35 \%$ of the outcomes, the statistical analysis did not produce conclusive results. Results also indicated that out of ten demographic factors considered in the analysis, four factors ("gender", "ethnicity", "course load" and "SAT math scores") did not have any impact on student learning. In other words, the modules are neutral to these factors. At the other end of the spectrum, students' "cumulative GPA" turned out to be a significant factor in five of the nine modules (55\%). This means that the high "cumulative GPA" group of students benefited disproportionately from the use of modules as compared to the low "cumulative GPA" group. Other demographic factors such as "age", "SAT verbal score" and "student track" were significant factors in only one of the nine modules (11\%) and "student level" was a significant factor in enhancing student learning in only two of the nine modules (22\%).

\section{Faculty Development}

Faculty development is another major benefit of this project. Most engineering faculty involved in this project had little or no prior experience in the use of simulation and visualization for enhancing quality of instruction. The project provided participating faculty members opportunities for professional development as they engaged in the development and implementation of web-based simulation and visualization modules for their courses. Assessment was another area in which project participants had little or no exposure prior to initiation of the DLR project. As the project matured, faculty participants became more knowledgeable and enthused about assessment methods, experimental design and statistical analysis techniques. In this regard, it is worth noting that a considerable transfer of knowledge occurred from assessment experts in the project team to other members.

\section{Pedagogical Contributions}

Finally the project has also made pedagogical contributions to engineering education. The investigators have been able to establish that the "pedagogy of supplementation", used in this project, was effective in enhancing student learning. The 
pedagogy combines in class instruction, the primary source of student learning in a typical on-campus setting, with learning in virtual environment - the supplementary source of learning - to create a learning environment that is interactive and engaging. Assessment results for modules used in two laboratory courses (solid mechanics lab and thermofluids lab) also show that the web-based virtual prelab practice sessions - a form of supplementation of physical experiment sessions - were effective in enhancing student learning of the experimental procedure, data acquisition and expected outcomes of experiments.

\section{Acknowledgement}

The authors acknowledge the financial support from the NSF grant EEC - 0530365 awarded through the Division of Engineering Education and Centers. Any opinions, findings, conclusions or recommendations expressed in this paper are those of the authors and do not necessarily reflect the views of the National Science Foundation.

\section{References}

[1] National Science Board, " Moving Forward to Improve Engineering Education",2007

[2] Catalano, GD. And Catalano, K. "Transformation fromTeacher-Centered to Student-Centered Engineering Education", Journal of Engineering Education, 1999, pp 5964.

[3] Felder, R.M., " Learning and Teaching Styles in Engineering Education", Journal of Engineering Education, 78(7), 1988, pp 674-681

[4] Reyes, M.E., "Unique Challenges of Women in Color in STEM Transferring from Community Colleges to Universities", Harvard Educational Review Summer, 2011, pp. 241-263.

[5] President's Council of Advisors on Science and Technology, "Engage to Excel", 2012

[6] Bourne, J. ,Harris, D and Mayadas, F., "Online Engineering Education : Learning Anywhere, Anytime", Journal of Engineering Education, 2005,pp.131-146

[7] Dutton, J., Dutton, M., and Perry, J., "Do Online Students perform as well as Lecture Students?" Journal of Engineering Education, 2001, pp. 131-136.

[8] McClanation , E.B. and McClanation, L.L., "Active Learning in a Non-Majors Biology
Class," College Teaching, Vol .50 ,2002,pp 9296

[9] Fagen, A.P., Crouch, C.H. and Mazur, E, "Peer Instruction: Results from a Range of Classrooms", Physics Teacher, Vol.40,2002.

[10] Hake, R.R., "Interactive Engagement Versus Traditional Methods. A Six-Thousand-Student Survey of Mechanics Test Data in Introductory Physics Courses", American Journal of Physics, Vol.66, 1998, pp.64-74.

[11] Capon, N and Kuhn, D., "What's So Good About Problem-Based Learning?", Cognition and Instruction, Vol.22,2004,pp 61-79.

[12] Freeman, M. et al., "Factors Affecting Educational Innovation With In Class Electronic Response System", Australasian Journal of Educational Technology, Vol.23, 2007, pp. 149170

[13] Ozer, T. et al., "On Developments in Interactive Web-based Learning Modules in ThermalFluids Engineering Course", Int. Journal of Engineering Education", Vol.19, 2003, pp. 305315.

[14] Chaturvedi,S.K. et al. "A Web-based Virtual Supersonic Module as an Interactive Visualization Tool for Teaching Concepts Related To One-Dimensional Gas Dynamics", Computers in Education Journal,2006,pp. 8089

[15] Chaturvedi,S. and Abdel-Salam, T. "Virtual Assembly Web-Based Student Learning tool for Thermodynamics Concepts Related to Multistaging in Compression and Turbines",Innovations 2008 World Innovations in Engineering Education and Research", 2008.

[16] Floris, R.E.,Koen,M.A. and Oglesby, D.B., "Basic Engineering Software for Teaching(BEST) Dynamics", Journal of Engineering Education, Vol.85,1996, pp. 61-67.

[17] Wankat, P.C., "Integrating the Use of Commercial Simulators into Lecture Classes", Journal of Engineering Education, Vol.91, 2002, pp.89-95.

[18] Chaturvedi, S.K.,Abdel Salam, T. M., "Development of a Methodology to Visualize and conduct a Physical Experiment as a Webbased Virtual Experiment", Proceedings of the Fourth IASTED International Conference on Web-Based Education, Grindelwald, Switzerland, February 2005. 
[19] Chaturvedi, S.K.,Abdel Salam, T.A., Muthoju, P.,Shrinivas, S., and Gagrani, V., "Mapping of a Thermo-fluids Laboratory Experiment into a Web-based Virtual Experiment for Application as a Prelab Practice Tool" INNOVATIONS 2007: World innovations in Engineering Education and Research, Chapter 28, ISSN 1553-9911, ISBN 978-0-9741252-6-8, August 2007.

[20] Swanson, D.K., and Lynch, C. S., "Web lab: A New Approach to Undergraduate ME laboratory Training at Georgia Tech," Proceedings of 2003 American Society of Engineering Education Annual Conference and Exposition, Session 3556 . A c c e s s i b 1 e a t http://soa.asee.org/paper/conference/paperview.cfm?id=18961

[21] Penarrocha, V. M. et al., "Virtual Laboratories in Electronic Engineering Education," International Conference on Network Universities and e-learning, May 2003, Valencia, Spain.

[22] Bhargava et al., Web-Based Virtual Torsion Laboratory, Wiley Periodical Inc. 2006.

[23] Bean, J.C., and Vijaykumar, V., " The Creation Of Web-Based Interactive Virtual Experiments on Microelectronics and Nanoscience for Early Engineering Students" ,IEEE/ASEE Frontiers in Educational Conference, 2002, Boston, MA

[24] Jia, R. et al., "A Virtual Laboratory on Fluid Mechanics", ASEE Annual Conference,2006. A c c e s s i b 1 e a $\mathrm{t}$ http://soa.asee.org/paper/conference/paperview.cfm?id=2194

[25] Buddu, M., "Virtual Laboratories for Engineering Educations," International
Conference on Engineering Education, August 2002.

[26] Hashemi, J. et al., "Web-Based Delivery of Laboratory Experiments and its Effectiveness Based on Student Learning Style," ASEE Annual Conference,2006. Accessible at http://soa.asee.org/paper/conference/paperview.cfm?id=2211.

[27] Olds,B.M.,Moskal, B.M. and Miller, R.L., "Assessment in Engineering Education Evolution, Approaches and Future Collaborartions", Journal of Engineering Education",2005, pp. 13-22.

[28] Tuckman, B.W., "Conducting Educational Research", Harcourt Brace Jovanovich Publishers, Florida, 1988.

[29] 29. Kashy, D. et al., " Teaching With ALN Technology: Benefits and Costs," Journal of Engineering Education, Vol.90,2001,499505

[30] Nguyen, J. Paschal, C., "Development of Online Ultrasound Instructional Module and Comparison to Traditional Teaching Methods", Journal of Engineering Education, Vol.91, 2001, pp. 278-283.

[31] Family Educational Rights and Privacy Act(FERPA),(1974), 20 U.S.C 1232g; 34 CFR Part 99, August 21, 1974.

[32] Shapiro, S.S. and Wilk, M.B.(1965),"An Analysis of Variance Test for $\mathrm{N}$ o r m a 1 i t y ( c o m p 1 e $\mathrm{t}$ e samples),"Biometrika,5:591-611.

[33] Wilcoxon,F. (1945). "Individual comparisons by ranking methods", Biometric Bulletin, 1,80-83. 
Table 1. P values for Different Outcomes

\begin{tabular}{|c|c|c|c|c|c|c|c|}
\hline $\begin{array}{c}\text { Courses } \\
\text { \Outcomes }\end{array}$ & Course Title & Quiz\#1 & Quiz\#2 & Quiz\#3 & Quiz\#4 & Quiz\#5 & $\begin{array}{l}\text { Quiz } \\
\text { Total }\end{array}$ \\
\hline $\begin{array}{c}\text { ME } 305 \\
\text { (Module 1) }\end{array}$ & $\begin{array}{c}\text { Thermo-Fluids } \\
\text { Laboratory }\end{array}$ & 0.0278 & 0.0165 & - & - & - & 0.01 \\
\hline $\begin{array}{c}\text { ME } 305 \\
\text { (Module 2) }\end{array}$ & $\begin{array}{c}\text { Thermo-Fluids } \\
\text { Laboratory }\end{array}$ & 0.001 & - & - & - & - & 0.01 \\
\hline ME 220 & Solid Mechanics & 0.0028 & 0.25 & - & - & - & 0.0083 \\
\hline ME 303 & $\begin{array}{l}\text { Mechanics of } \\
\text { Fluids }\end{array}$ & 0.001 & 0.003 & 0.1325 & 0.001 & - & 0.001 \\
\hline ME 225 & $\begin{array}{c}\text { Solid Mechanics } \\
\text { Laboratory }\end{array}$ & 0.0221 & 0.0119 & - & - & - & 0.0062 \\
\hline ME 205 & Dynamics & 0.0074 & 0.3422 & 0.002 & - & - & 0.0023 \\
\hline $\begin{array}{c}\text { ME } 311 \\
\text { (Module 1) }\end{array}$ & Thermodynamics I & 0.0034 & 0.0058 & - & - & - & 0.071 \\
\hline $\begin{array}{c}\text { Me } 311 \\
\text { (Module 2) }\end{array}$ & Thermodynamics I & 0.106 & 0.1721 & 0.0273 & - & - & 0.2132 \\
\hline ECE 201 & Circuits Analysis & 0.102 & 0.0908 & 0.018 & 0.193 & - & $\begin{array}{c}0.0015 \\
7\end{array}$ \\
\hline CEE 350 & $\begin{array}{c}\text { Environmental } \\
\text { Polloution }\end{array}$ & 0.6882 & 0.1426 & 0.184 & 0.0684 & 0.0248 & 0.0449 \\
\hline
\end{tabular}


Table 2. Summary of Results from the Statistical Analysis of Demographic Factors

\begin{tabular}{|c|c|c|c|c|c|c|c|c|c|c|}
\hline Course & Gender & Ethnicity & $\begin{array}{c}\text { Student } \\
\text { Level }\end{array}$ & Age & $\begin{array}{l}\text { Class } \\
\text { Load }\end{array}$ & $\begin{array}{l}\text { Cum. } \\
\text { GPA }\end{array}$ & Track & $\begin{array}{c}\text { SAT } \\
\text { Verbal }\end{array}$ & $\begin{array}{l}\text { SAT } \\
\text { Math }\end{array}$ & $\begin{array}{c}\text { HS } \\
\text { GPA }\end{array}$ \\
\hline $\begin{array}{c}\text { ME } 305 \\
\text { (Module 1) }\end{array}$ & NO & NO & NO & NO & NO & NO & NO & NO & NO & $\mathrm{NO}$ \\
\hline $\begin{array}{c}\text { ME } 305 \\
\text { (Module 2) }\end{array}$ & NO & NO & NA & $\mathrm{NO}$ & NA & NO & YES & NA & NO & YES \\
\hline ME 220 & NO & NO & NO & $\mathrm{NO}$ & NO & NO & NO & NO & NO & NO \\
\hline ME 303 & NO & NO & NO & NO & NO & YES & NO & YES & NO & NO \\
\hline ME 225 & NO & NO & NO & NO & NO & NO & NO & NO & NO & NO \\
\hline ME 205 & NO & NO & NO & $\mathrm{NO}$ & NO & YES & NO & NO & $\mathrm{NO}$ & YES \\
\hline $\begin{array}{c}\text { ME } 311 \\
\text { (Module 1) }\end{array}$ & NO & NO & YES & YES & NO & YES & NO & NO & NO & NO \\
\hline $\begin{array}{c}\text { Me } 311 \\
\text { (Module 2) }\end{array}$ & NO & NO & YES & $\mathrm{NO}$ & NO & YES & NO & NO & NO & NO \\
\hline ECE 201 & NA & NA & NA & NA & NA & NA & NA & NA & NA & NA \\
\hline CEE 350 & NO & NO & NO & $\mathrm{NO}$ & NO & YES & $\mathrm{NO}$ & NO & NO & YES \\
\hline
\end{tabular}

NO: Factor Not Significant

NA: Factor Not Available

YES: Factor Significant 